\title{
Prosody and comprehension of ambiguous dative NPs in Korean
}

\author{
Kang, Soyoung1)
}

\begin{abstract}
The current study reports the results from a cross-modal naming experiment investigating the effects of a prosodic boundary location on the comprehension of ambiguous dative NPs in Korean (Yeongmi-ka Ceonghi-eykey norae-rul pwulecwu-n pwuin-ul …). The underlined dative NP, Ceonghi-eykey, can temporarily be attached to the embedded rel-marked verb, pwulecwu- $n$ ('sing-rel') or to the matrix verb to appear later. Participants heard sentence fragments manipulated for the location of Intonation Phrase boundary (the biggest prosodic boundary in the model of Seoul Korean) and right after that, had to name visually presented naming targets, which resolve the ambiguity of dative NPs. The prosodic manipulation did not result in difference in naming time, suggesting that the location of a prosodic boundary failed to influence the way Korean listeners interpreted ambiguous dative NPs. Possible reasons for the null effect were discussed.
\end{abstract}

\section{Keywords: syntactic ambiguity, Korean dative NPs, prosodic boundary, a cross-modal naming task}

\section{Introduction}

In recent years, a considerable number of studies have investigated the way native speakers of a given language process sentences in the spoken context, focusing on the role of prosodic structure in the comprehension of syntactically ambiguous sentences. Numerous studies have found consistent effects of prosodic structure on the resolution of syntactic ambiguity not only with overt prosody (Price, Ostendorf, Shattuck-Huffnagel \& Fong, 1991; Kjelgaard \& Speer, 1999; Schafer, 1997; Schafer, Speer, Warren \& White, 2000; Schafer, Speer \& Warren, 2004, among others) but even with implicit prosody (Hirose, 2003; Hwang \& Schafer, 2009; Jun, 2003; Jun \& Koike, 2003).

Among diverse syntactic structures that have been found to be affected by overt prosodic structure, syntactic clause boundary ambiguity has been frequently examined for typologically different languages (e.g., Kang \& Speer, 2003 for Korean relative clause ambiguity; Misono, Mazuka, Kondo \&

1) Hongik University, kang139@gmail.com

Received: May 13, 2014

Revised: June 11, 2014

Accepted: June 12, 2014
Kiritani, 1997 for Japanese participle construction ambiguity; Kang, Speer \& Nakayama, 2006 for Japanese relative clause ambiguity; Kjelgaard \& Speer, 1999; Schafer et al., 2000; Schafer et al., 2004 for English early vs. late closure ambiguity). What these studies confirmed was that prosodic boundaries matching with syntactic boundaries provided helpful cues for listeners' locating otherwise ambiguous syntactic clause boundaries.

In addition, some of these studies (Kang \& Speer, 2003; Kang et al., 2006) have further argued that prosodic phrasing cues seem to play a bigger role in identifying syntactic clause boundaries for head final languages such as Korean or Japanese. Unlike English, syntactic clause boundaries in Korean are hard to locate early in the sentence because of the lack of an overt lexical complementizer, the marker of an embedded clause occurring only as a morpheme attached to the embedded verb, and the existence of an empty pronoun, pro. Given the sequence of $\mathrm{NP}_{1}$ nom V.rel (Yengman-ika tallyeoka-nun ...), for example, there is no way to tell whether or not the rel-marked verb belongs to the same clause as the nom-marked $\mathrm{NP}_{1}$. However, the presence or absence of a prosodic boundary right after the initial nom-marked NP in sequences like this was shown to exert a very strong effect in the way Korean listeners understood the ambiguous rel-marked verb (Kang \& Speer, 
2003). With the prosodic boundary right after the initial nom-marked NP, listeners tended not to attach the rel-marked verb to the nom-marked NP, whereas without the same prosodic boundary, listeners were more likely to attach the rel-marked verb to the initial nom-marked NP. Based on this, these authors argue that this may result from the characteristics of prosodic structure of Korean. Unlike English, where lexical property of a word such as stress heavily contributes to possible intonation patterns of a given language and has a potential to influence syntactic attachment decision (e.g., Schafer, Carter, Clifton \& Frazier, 1996), Korean lacks such a lexical property and so it would be possible for prosodic phrasing to assume more roles. Of course, this does not suggest that prosodic boundary information in languages like English is less informative or less effective in perceiving syntactic boundaries. Instead, since Korean allows much more ambiguous syntactic clause boundaries and formation of Korean prosodic structure may not be influenced from lexical property of a word such as stress as heavily as English, there will be more room that prosodic boundary information can be utilized in the resolution of ambiguous syntactic clause boundaries in Korean more often.

The current study extends this line of research and investigates if a prosodic boundary can change the attachment of the ambiguous dat-marked $\mathrm{NP}$ in the sequence of $\mathrm{NP}_{1-n o m}$ $\mathbf{N P}_{2-\text { dat }} \mathrm{NP}_{3-\text { acc }} \ldots$ in Seoul Korean, using an on-line method, a cross-modal naming task. In this type of task, listeners hear a sentence fragment, have to name verbally a visually presented disambiguating word, and then complete the sentence with their own words. Time latency to name this disambiguating word reflects easiness or difficulty with which listeners integrate this visual target into the previous materials they heard. Unlike off-line tests such as the end of the sentence comprehension task, or grammaticality judgment task where different sources of information are available to comprehenders at the end of the sentence, on-line methods including a cross-modal naming task can assess the effects of certain information at various temporal points of the sentence without waiting for the end of the sentence, thereby demonstrating the immediate availability of such information. Prosodic effects on syntactic closure ambiguities using a cross-modal naming task have been attested in several studies for English (Kjelgaard \& Speer, 1999; Warren, Grabe \& Nolan, 1995; Marselen-Wilson, Tyler, Warren, Grenier \& Lee, 1992). The current study manipulated the location of a prosodic phrase boundary (Intonation Phrase boundary in Jun's model of Seoul Korean (1993)) either before or after the ambiguous dat-marked NP and saw if the prosodic manipulation affected listeners' response time to name the visual target. If listeners' naming latency to the same naming target differs in two different conditions, this indicates that the differing prosody will be the factor that affected listeners' integration of the visual target into the auditory materials they have heard.

\section{Target constructions}

The materials to be examined in this study are given in (1) below. Due to the lack of a marker for the beginning of an embedded clause and the possibility for positing pro in Korean, the dat-marked NP, Ceonghi-eykey, in this sequence can either be analyzed as a clause mate of the initial nom-marked NP, Yeongmi-ka, or belong to the embedded clause along with the first acc-marked NP, norae-rul, as a dative argument of the rel-marked verb pwulecwu- $n$. If the dat-marked NP is analyzed as a clause mate of the initial nom-marked NP, then, pro will be posited for the dative argument of the embedded verb, a ditransitive verb, until the disambiguating main verb occurs.

\begin{tabular}{|c|c|c|}
\hline (1) Yeongmi-ka & Ceonghi-eykey & norae-rul \\
\hline name-nom & name- dat & song-acc \\
\hline pwulecwu-n & pwuin-ul & \\
\hline sing-rel & lady-acc & \\
\hline
\end{tabular}

This ambiguity is resolved if the sequence is followed by a transitive verb such as ttaraka-ss-e ('followed') as in (2) below.

\begin{tabular}{|c|c|c|}
\hline 2) Yeongmi-ka & Ceonghi-eykey & norae-rul \\
\hline name-nom & name- dat & song-acc \\
\hline pwulecwu-n & pwuin-ul & ttaraka-ss-e. \\
\hline sing-rel & lady-acc & follow-past-dec \\
\hline
\end{tabular}

'Yeongmi followed the lady who sang a song for Ceonghi.'

At the point of the matrix verb ttaraka-ss-e ('followed'), it becomes clear that the dat-marked NP should belong to the relative clause because the matrix verb cannot take a dative NP as one of its arguments. However, at the point of processing the dat-marked NP, there is no knowing that the dat-marked NP belongs to the matrix verb, ttaraka-ss-e ('followed'), or the embedded verb, pwulecwu-n ('sing-rel').

For similar sentences containing an ambiguous dat-marked NP, Koh (1997) and Kamide \& Mitchell (1999) reported that 
both Korean (Koh, 1997) and Japanese (Kamide \& Mitchell, 1999) readers preferred to attach the dat-marked NP to the matrix verb that has yet to come. Applying this to the current materials, we can say that the dat-marked NP will be preferably attached to a higher clause, that is, as a clause mate of the initial nom-marked NP and that when the parser encounters the matrix verb requiring only the acc-marked NP, the initially high-attached dat-marked NP will be expelled into the embedded clause, whose verb can take both a dat-marked NP and an acc-marked NP. In the final interpretation, a syntactic clause boundary comes right before the dat-marked NP although the parser may not realize it until later, when it encounters the matrix verb.

The current study manipulated an Intonation Phrase (IP, henceforth) boundary, the biggest prosodic unit in Jun (1993)'s model of Seoul Korean. An IP boundary, in this model, is typically accompanied by phrase final lengthening and an optional pause, and marked by one of IP boundary tones (L\%, $\mathrm{H} \%, \mathrm{HL} \%$, LHL\%, etc.). An IP contains one or more Accentual Phrases (AP, henceforth), the lower prosodic unit, which does not have perceivable phrase final lengthening. An AP is characterized by its underlying tonal pattern, THLHa, with the initial $\mathrm{T}$ being realized as an $\mathrm{L}$ tone unless the initial segment is either tense or aspirated, in which case $\mathrm{T}$ is realized as an $\mathrm{H}$ tone. The underlined $\mathrm{H}$ tone is typically aligned with the second syllable in an AP, while the final $\mathrm{H}$ tone (represented as $\mathrm{Ha}$ ) is realized on the AP final syllable. All four tones are realized when an AP contains four or more syllables, whereas the middle two tones may be deleted in an AP with less than four syllables.

The manipulated IP boundary was placed at two different locations to see if the presence of this prosodic boundary at those locations can affect listeners' integration of the visual target into the auditory fragment of the test sentence. Since the final interpretation requires the ambiguous dat-marked NP to be attached to the embedded verb, which means the syntactic clause boundary comes right before the dat-marked NP, the presence of an IP boundary at this location (the matching condition) was expected to further help the listener to pursue this analysis and ultimately facilitate the integration of the final matrix verb into the spoken sentence fragment more easily. On the other hand, if the IP boundary comes after the dat-marked NP (the conflicting condition), then, listeners would be led toward the incorrect interpretation that the dat-marked NP belongs to the same clause as the initial nom-marked NP as an argument of the matrix verb to appear. When the matrix verb appears as a naming target, it was predicted that listeners would experience difficulty in integrating the verb, which does not meet their expectation for a verb that can take the dat-marked NP.

\section{Experiments}

\subsection{Participants}

A total of 20 native speakers of Korean recruited from a university in Korea participated in this study for monetary compensation.

\subsection{Materials}

A total of 18 test sentences such as (2) were created (all test sentences are provided in the appendix) and combined with materials testing separate syntactic structure, which consisted of 18 sentences, and finally 24 unrelated fillers. In sum, 60 sentences were presented to each participant with differing prosodic phrasings. The location of an IP boundary was manipulated for each sentence. For the early IP condition (EIP), the matching condition, the IP boundary was placed earlier, right before the ambiguous dat-marked NP as in (3a) below, whereas for the late IP condition (LIP), the conflicting condition, the IP boundary was placed later, after the ambiguous dat-marked NP as in (3b).

$\begin{array}{ccl}\text { (3) a. }[[\text { isscanha }]] I P & {[[\text { Yeongmi-ka }]] I P} & {[[\text { Ceonghi-eykey }] \text { AP }} \\ {[\text { norae-rul }} & \text { pwulecwu-n } & \text { pwuin-ul }] \text { AP }\end{array}$ [ttaraka-ss-e]AP]IP : early IP (matching condition)

b. [[isscanha]]IP [[Yeongmi-ka]AP [Ceonghi-eykey]AP]IP [[norae-rul pwulecwu-n pwuin-ul]AP

ttaraka-ss-e]AP]IP : late IP (conflicting condition)

Two prosodic versions of each test sentence such as (3) were produced by a female native speaker of Seoul Korean, who was a phonetician familiar with Korean intonation system. The followings should be taken notice of for (3). First, each sentence begins with one of sentence starters such as isscanha (있잖아)', 'sasil-un (사실은)', 'kunde malya (근데 말야)' (the underlined part in (3)). This was to ensure that the speaker can produce each sentence as if it is a part of an actual conversation with close acquaintances, and to prevent the speaker from accidentally putting each word into each AP. ${ }^{2)}$ Second, in the last IP in (3a), the first word (Ceonghi-eykey) 
was produced as one separate AP and then the next three words formed another AP, whereas for (3b), the second IP contains two words, each of which was produced as a separate AP and in the final IP, the first three words were produced as one AP.

From this original production of each sentence, the word to serve as the naming target (the bold-faced part), the matrix verb, ttaraka-ss-e, was truncated out of each recorded sound file and the remaining sentence fragments were saved and used as auditory stimuli for the experimental task. Pitch contours of these two prosodic versions without the final matrix verb are presented in $<$ Figure $1>$ (for EIP) and $<$ Figure $2>$ (for LIP) below.

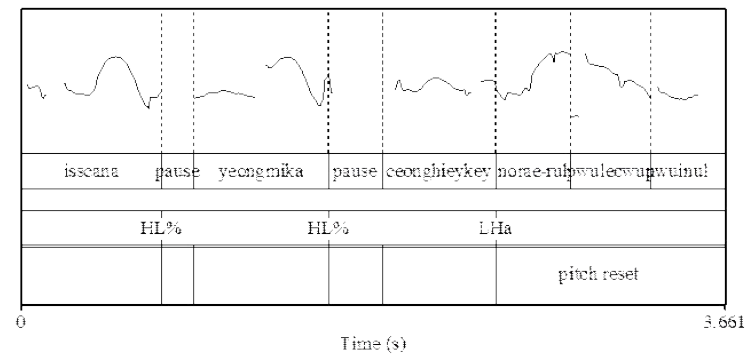

Figure 1. Pitch contour of an early IP condition (EIP)

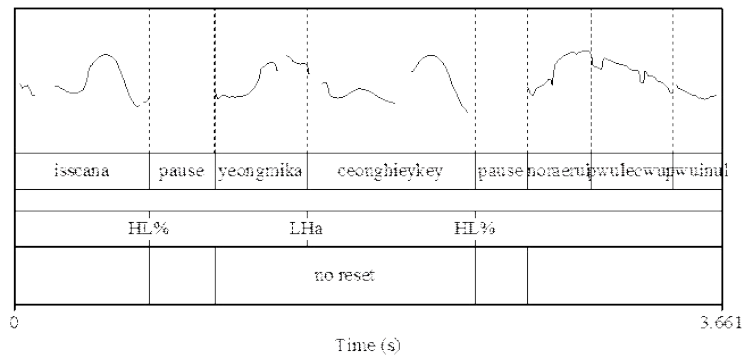

Figure 2. Pitch contour of a late IP condition (LIP)

The analysis of duration for two critical locations (to be discussed below) from each sentence confirmed that each sentence was produced as intended. As discussed before, an IP final syllable is lengthened and often followed by a pause. For the early IP (EIP) condition, the IP boundary was inserted right after the initial nom-marked NP, Yeongmi-ka, and therefore, the IP boundary final ' $k a$ ' from this nom-marked NP was considerably lengthened and accompanied by a long pause (the

2) It seems that native speakers of Korean have a strong tendency to put each lexical word into one separate Accentual Phrase (e.g., Jun \& Kim, 2004) in a laboratory setting when asked to read directly from a text. mean duration of ' $\mathrm{ka}$ ' and the following pause was $722 \mathrm{~ms}$ ). On the other hand, in the late IP condition (LIP), ' $\mathrm{ka}$ ' in the same NP came at the AP final position (see (3b)), where no syllable lengthening or pause occurred and therefore, its duration was much shorter (mean $154 \mathrm{~ms}$ ). For 'key' from the ambiguous dat-marked NP, Ceonghi-eykey, the opposite pattern was observed; since the IP boundary was inserted right after the 'key' marked NP in the late IP condition, the duration of 'key' and any following pause was much longer in this condition (mean $667 \mathrm{~ms}$ ) than in the early IP condition (mean $161 \mathrm{~ms}$ ). The summary is provided in $<$ Table $1>$ below.

Table 1: Mean duration of ka + pause and key + pause in two prosodic conditions

\begin{tabular}{|c|c|c|}
\hline $\mathrm{ms}$ & $\mathrm{ka}+$ pause (SD) & key + pause (SD) \\
\hline EIP & $722(45)$ & $161(27)$ \\
\hline LIP & $154(26)$ & $667(96)$ \\
\hline
\end{tabular}

$<$ Figure $3>$ shows the duration of 'ka' and 'key' along with any following pause of each test sentence in two prosodic conditions.

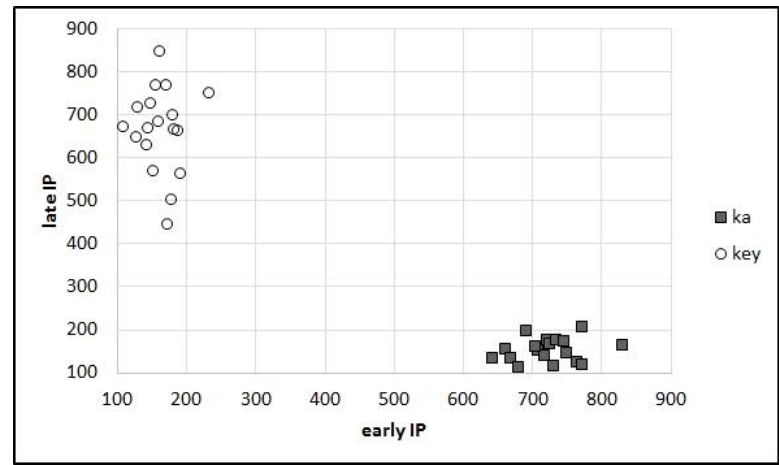

Figure 3. Duration of ka+pause and key+pause of each sentence in two prosodic conditions

A statistical analysis of duration measurement of these two locations was conducted. One way ANOVA conducted using $\mathrm{R}$ (a free statistical analysis program) ${ }^{3}$ ) confirmed that there was a significant difference between EIP and LIP conditions [F $(1,34)$ $=2017, \mathrm{p}<.001]$ for ' $\mathrm{ka}$ ' and following pauses, and for 'key' and following pauses $[\mathrm{F}(1,34)=434.2, \mathrm{p}<.001]$

Finally, note that the visual target to name, the matrix verb, will be presented in a slightly modified form. For example, in

3) All subsequent statistical analyses were conducted using this program. 
(3), the verb ttaraka-ss-e ('따라갔어') will be presented as ttaraka-ss-nunde ('따라갔는데') so that participants can continue with their own words to complete the sentence. If a participant's completion turns out to make the sentence ungrammatical in one condition but not in the other, this would indicate that that particular condition would be leading listeners to build a particular, eventually wrong syntactic structure.

The two prosodic versions of 18 test sentences were allocated in two different lists (9 EIP sentences and 9 LIP sentences in each list) and pseudo-randomized with 42 filler sentences so that no three test sentences occurred in a row. This way, only one prosodic version of these 18 sentences was included in each list and participants heard only one version of each test sentence.

\subsection{Procedure}

The experiment consisted of a practice session and two main sessions. Before each experimental session started, each participant was briefed about the experimental procedure in Korean by the experimenter orally. Participants were given time to ask questions on any unclear points. When they indicated they were ready, the experiment began. The procedure of the first main session was as follows. First, in each trial, participants heard a sentence fragment over the headphones. Right after hearing the sentence fragment, they saw a visual target (i.e., the matrix verb with inflection such as ttaraka-ss-nunde '따라갔는데' for sentence (3), presented in the Korean orthography) on the computer monitor and had to name that word into the microphone connected to the computer as fast and accurately as possible. After naming the visual target, participants had to add at least one more word to complete the sentence and then answer a comprehension question presented on the monitor by pressing one of three buttons on the response box. For the second main session, participants had to name the same visual stimuli in isolation, this time without hearing any spoken fragments or adding any words. This second part was to measure the base-line response time to name each target word without any lexical or contextual influence (see Kjelgaard \& Speer, 1999). By obtaining this base-line response time to each naming target and subtracting this from response times to each naming target in two different prosodic conditions, any variability of the target item will be equally corrected for two different conditions (refer also to the Results section). Before these two main sessions, participants completed 5 practice trials and after that if they still had questions, they had a chance to ask questions again but once they started, they were not allowed to talk to the experimenter. For the first main session of the experiment, the completions provided by each participant were recorded on paper by the experimenter, who was sitting right next to the participant. For the comprehension questions, how the dative NP was understood was probed with a question such as (4) below. The questions and three choices were presented in the Korean orthography as well.
(4) $[$ isscanha $] I P \quad[$ Yeongmi-ka]IP [Ceonghi-eykey norae-rul pwulecwu-n pwuin-ul target Q: Nwukwu-eykey norae-rul pwulecwu-ess-na? For whom was the song sung?
a. Yeongmi
b. Ceonghi
c. the lady

\subsection{Results}

The analyses of naming errors, naming latency, and accuracy on comprehension questions were conducted. Naming errors included any data for which participants' completions were judged ungrammatical, no completions were provided, participants had to name the visual target twice, or data that took longer than $3000 \mathrm{~ms}$. These naming errors accounted for $6 \%$ of the whole data for the early IP condition, and $4 \%$ for the late IP condition.

The analysis of naming latency excluded any data that were judged naming errors as described above and the response time for those data were replaced by the mean of that participant's mean of all test items and the mean of that particular item contributed by all participants, following the procedure from Kjelgaard \& Speer (1999). For example, if participant 10 in List 1 had a naming error for test item 10, then, first, the mean of this participant's response time to all test items excluding this item was calculated (say $1500 \mathrm{~ms}$ ). Then, the mean response time of test item 10 from all the participants excluding participant 10 was calculated (say $2000 \mathrm{~ms}$ ). The mean of these two numbers $(1750 \mathrm{~ms})$ was used for the naming error item for this participant. Finally, the naming time was corrected for any possible lexical and contextual effects by subtracting the naming time for each item in isolation from the naming time for each item in two prosodic conditions. The mean response time for each prosodic condition obtained from this process was summarized in $<$ Table $2>$. 
Table 2: Mean naming latency and accuracy for comprehension questions in two prosodic conditions

\begin{tabular}{|c|c|c|}
\hline & EIP (SD) & LIP (SD) \\
\hline Naming latency & $279(147) \mathrm{ms}$ & $295(183) \mathrm{ms}$ \\
\hline Accuracy & $32 \%$ & $28 \%$ \\
\hline
\end{tabular}

Although numerically, EIP, the matching condition, was faster in naming the visual targets overall $(279 \mathrm{~ms})$ than LIP (295 $\mathrm{ms}$ ), the conflicting condition, one way repeated measures ANOVA with corrected response time as a dependent variable showed that the difference between two prosodic conditions was not significant on either subject analysis $\left[F_{1}(1,19)=0.442, p>\right.$ $.5]$ or item analysis $\left[F_{2}(1,17)=0.19, \mathrm{p}>.6\right]$.

Accuracy on comprehension questions was also analyzed. Since the question was always about the dat-marked NP in the sentence and the final main verb cannot take the dat-marked $\mathrm{NP}$, the correct answer was supposed to be the dat-marked NP contained in the sentence fragment that participants heard. Despite this, the accuracy on the comprehension questions was relatively low, $32 \%$ for EIP, and $28 \%$ for LIP, as can be seen in $\langle$ Table $2>$. Again, although EIP, the matching condition, showed higher accuracy rate overall, one way repeated measures ANOVA with the arcsine transformed mean accuracy rate as a dependent variable showed that the difference between two prosodic conditions was not significant on either subject analysis $\left[F_{1}(1,19)=2.408, p=.137\right]$ or item analysis $\left[F_{2}(1,17)=\right.$ $1.463, \mathrm{p}=.243]$.

\section{Discussion and conclusion}

The current study investigated if prosodic manipulation affected Korean listeners' comprehension of sentences containing temporarily ambiguous dat-marked NPs. In terms of naming latency, although numerically, the early IP condition, which matched with a syntactic clause boundary, was faster than the late IP condition, which eventually does not match with such a boundary, this tendency was not supported by a statistical analysis. Accuracy on comprehension questions also pointed to the same direction.

Several reasons for this null effect could be suggested. First, prosodic boundary information is ineffective in the resolution of dative NP ambiguity in Seoul Korean. However, given numerous studies that have demonstrated prosodic effects on the resolution of syntactic ambiguity (e.g., Kjelgaard \& Speer, 1999;
Schafer et al., 2004, for English; Kang \& Speer, 2003; Kong, 2010 for Korean; Misono et al., 1997 for Japanese), this conclusion would be too premature. Secondly, the sentence structure, which contains as many as 4 referential NPs, might have caused a heavy processing difficulty to the extent that the prosodic manipulation did not play any role. Compared to pronominal expressions, referential NPs such as proper nouns or definite NPs have been known to cause more processing difficulty in relative clause comprehension (e.g., Warren \& Gibson, 2002). In addition, the naming target comes fairly later, after processing 6 lexical items (4 of them are referential NPs), by which point, listeners' processing load would have been already so heavy that they failed to pay attention to prosodic difference. This possibility seems to be supported by the low accuracy on comprehension questions. Finally, some unforeseen factor in prosodic phrasing might have come into play. Remember that in <Figure $1>$, the last IP beginning with Ceonghi-eykey has two APs, the first of which was the ambiguous dat-marked NP, Ceonghi-eykey, and the second AP consisted of the remaining three words. Further to be noted was the fact that the second AP beginning with norae-rul was produced with a higher $\mathrm{H}$ tone starting at the second syllable in norae-rul than the $\mathrm{H}$ tone on the second syllable in the preceding AP, Ceonghi-eykey. This deviates from a typical tonal pattern of multiple APs within the same IP where each successive $\mathrm{AP}$ has a lower initial $\mathrm{H}$ tone in the underlying THLHa, and suggests that the second AP was produced with pitch range reset. Compare this pitch range reset pattern with the case with no pitch range reset in an IP, the second IP in $<$ Figure 2>.4) A close examination of test materials revealed that almost all EIP sentences were produced with this kind of pitch range reset,5) and it is suspected that this pitch range reset across APs in the same IP may have played a role in listeners' attachment decision.

Although the role of pitch range reset in Korean sentence processing has begun to be examined only recently, Kong (2010), in fact, showed that pitch range reset can affect Korean listeners' attachment decision, using ambiguous participle constructions in Korean. For a sentence like (5) below, she

4) The higher $\mathrm{H}$ tone on the last syllable of the second AP, Ceonghieykey in $<$ Figure $2>$, denotes a part of $\mathrm{HL} \%$, one of IP final tones, which replaces the typical Ha tone in an AP that comes at the end of an IP.

5) 14 out of 18 sentences share the same laryngeal features in AP initial segments, making easier the comparison of two tones in two successive APs (see the appendix) 
found that when there was pitch range reset after the bold-faced ambiguous participle, Korean listeners were more likely to understand the initial NP, Unceong-iga, as the subject of the participle (i.e., toward (5a) reading) than when there was no such pitch range reset. This indicates that although the same AP exists before the ambiguous participle and the underlined rel-marked verb, the pitch range resetted rel-marked verb may have felt perceptually separate from the previous participle phrase, which, in turn, would group the participle phrase with the subject NP.

(5) Unceong-iga Uncenog-nom nwunulhulki-myense pabulmekko-issnun yehaksayng-ul stare at-part eat-prog-rel yatanch-ess-e. female student-acc scold-past-dec

a. Unceong, who was staring at her, scolded a female student who was eating.

b. Unceong, scolded a female student who was staring at her and eating.

Jun $(2006 ; 2007)$ also argued that pitch range reset plays a role in the attachment of ambiguous Korean relative clauses and that a new prosodic phrase (termed Intermediate Phrase and notated as ip), which can be signaled with pitch range reset, should be introduced in the intonation model of Seoul Korean. According to this revised model, the test sentence in (3a) can be reanalyzed as (6a), with an ip right after the ambiguous dat-marked NP. Then, even with the IP boundary right after the initial nom-marked NP, the dat-marked NP may have sounded separate from the following phrase starting with the acc-marked $\mathrm{NP}$, and this may not have been felt to be that different from the case with an IP at the same location (i.e., (6b)).

\section{(6) a.[[[isscanha] $]] I P \quad[[[Y$ Yeongmi-ka $]]] I P \quad[[$ Ceonghi-eykey $] \underline{p}$ [[norae-rul pwulecwu-n pwuin-ul $\ldots$ : early IP b.[[[isscanha]]]IP [[[Yeongmi-ka]AP Ceonghi-eykey]]]IP [norae-rul pwulecwu-n pwuin-ul $\cdots \quad$ : late IP}

Of course, if we consider "informative break hypothesis", proposed by Carlson, Clifton \& Frazier (2001) and Clifton, Carlson \& Frazier (2002), the idea that the smaller prosodic break, namely, ip in sentence (6a), plays a role in attachment decision does not sound very convincing because this hypothesis predicts that the global prosodic structure rather than the local prosodic boundary matters in the resolution of syntactic ambiguity. This would mean that an ip at a certain location would not be influential given the bigger prosodic boundary, the IP in an earlier position, which would sound stronger. However, at the same time, this would also mean that we could consider further leftward, the IP right after a sentence starter such as isscanha ('있잖아'), kunde malya ('근데 말야'), sasil-un ('사실 은'). For the early IP condition, the IP boundary existed right after this sentence starter, and after the initial nom-marked NP. It can be speculated that there might be some interaction of the two IPs in an earlier location and the ip at a later location, and this might have affected listeners' perception of the global prosodic structure of the sentence.

In conclusion, prosodic manipulation of an IP boundary in this study failed to affect the attachment decision by native speakers of Korean in the comprehension of ambiguous dative NPs in Korean. However, a possibility that a smaller prosodic break, marked by pitch range reset, may have a role in Korean sentence processing has also been brought up, and given some experimental findings favoring the presence of an ip in the intonation model of Seoul Korean, it is believed that this possibility should be further investigated in future study.

\section{References}

Carlson, K., Clifton, C., \& Frazier, L. (2001). Prosodic boundaries in adjunct attachment. Journal of Memory and Language, Vol. 45, No.1, 58-81.

Clifton, C., Carlson, K., \& Frazier, L. (2002). Informative prosodic boundaries. Language and Speech, Vol. 45, No.2, 87-114.

Hirose, Y. (2003). Recycling prosodic boundaries. Journal of Psycholinguistic Research, Vol. 32, No.2, 167-195.

Hwang, H., \& Schafer, A, J. (2009). Constituent length affects prosody and processing for a dative to NP ambiguity in Korean. Journal of Psycholinguistic Research, Vol. 38, No.2, 151-175.

Jun, S. (1993). The Phonetics and Phonology of Korean Prosody. $\mathrm{PhD}$ dissertation. Ohio State University. Columbus, $\mathrm{OH}$.

Jun, S. (2003). Prosodic phrasing and attachment preferences. Journal of Psycholinguistic Research, Vol. 32, No.2, 219-249. Jun, S. (2006). Intonational phonology of Seoul Korean revisited. In T.J. Vance \& K. Jones (Eds.), Japanese/Korean Linguistics 14, 15-26. CSLI: Stanford.

Jun, S. (2007). The Intermediate phrase in Korean intonation: Its role in sentence processing. In C. Gussenhoven \& T. Riad 
(Eds.), Tones and Tunes: Studies in Word and Sentence Prosody. 143-167. Berlin: Mouton de Gruyter.

Jun, S. \& Kim, S. (2004). Default phrasing and attachment preferences in Korean. In Proceedings of INTER SPEECH-ICSLP (International Conference on Spoken Language Processing), Jeju, Korea.

Jun, S \& Koike, C. (2003). Default prosody and relative clause attachment in Japanese. A talk given at the $13^{\text {th }}$ Japanese/Korean Linguistics Conference. East Lansing, Michigan.

Kamide, Y., \& Mitchell, D. (1997). Incremental pre-head attachment in Japanese parsing. Language and Cognitive Processes, Vol. 14, No.5/6, 631-662.

Kang, S., \& Speer, S.R. (2003). Prosody and syntactic clause boundary in Korean. In G. Garding \& M. Tsujimura (Eds). WCCFL 22 Proceedings, 259-272. Somerville, MA: Cascadilla Press.

Kang, S., Speer, S., \& Nakayama, M. (2006). Effects of intonational phrase boundaries on ambiguous syntactic clause boundaries in Japanese. In (Eds.)Japanese/Korean Linguistics 14, 77-88.

Kjelgaard, M. and Speer, S. (1999). Prosodic facilitation and interference in the resolution of temporary syntactic ambiguity. Journal of Memory and Language, Vol. 40, No.2, 153-194.

Koh, S. (1997). The resolution of the dative NP ambiguity in Korean. Journal of Psycholinguistic Research, Vol. 26, No. 2, 265-273.

Kong, E. (2010). The role of pitch range reset in Korean sentence processing. Journal of the Korean Society of Speech Sciences, Vol. 2, No. 1, 33-39.

Marselen-Wilson, W.D., Tyler, L.K., Warren, P., Grenier, P., \& Lee, C.S. (1992). Prosodic effects in minimal attachment. Quarterly Journal of Experimental Psychology. Vol. 45A, 73-87.

Misono, Y., Mazuka, R., Kondo, T., \& Kiritani, S. (1997). Effects and limitations of prosodic and semantic biases on syntactic disambiguation. Journal of Psycholinguistic Research, Vol. 26, No. 2, 229-245.

Price, P., Ostendorf, M., Shattuck-Huffnagel, S., \& Fong, C. (1991). The use of prosody in syntactic disambiguation. Journal of Acoustical Society of America, Vol. 90, 2956-2970.

Schafer, A. (1997). Prosodic parsing: The role of prosody in sentence comprehension. $\mathrm{PhD}$ dissertation. University of Massachusetts. Amherst, MA.

Schafer, A., Carter, J., Clifton, C., \& Frazier, L. (1996). Focus in relative clause construal. Language and Cognitive Processes, Vol. 11, No. 1/2, 135-163.

Schafer, A., Speer, S.R., Warren, P., \& White, S.D. (2000). Intonational disambiguation in sentence production and comprehension. Journal of Psycholinguistic Research, Vol. 29, No.2, 169-182.

Schafer, A., Speer, S., \& Warren, P. (2004). Prosodic influences on the production and comprehension of syntactic ambiguity in a game-based conversation task. In J.C Trueswell and M.K. Tanenhaus, (Eds). Approaches to studying world-situated language use: Bridging the action and product traditions. 209-225. MA: MIT Press.

Warren, P., Grabe, E., \& Nolan, F. (1995). Prosody, phonology and closure ambiguities. Language and Cognitive Processes, Vol. 10, 457-486.

Warren, T., \& Gibson, E. (2002). The influence of referential processing on sentence complexity. Cognition, Vol. 85, 79-112.

\section{- Kang, Soyoung \\ International Language Institute, Hongik University \\ 94 Wausan-ro Mapo-gu, 121-791, Seoul, Korea \\ Tel: 02-320-1368 Fax: 02-320-1374 \\ Email: kang139@gmail.com \\ Areas of interest: psycholinguistics, phonetics, syntax}

\section{Appendix}

*The words in the parentheses are the naming targets.

** The bold-faced parts are the words whose initial segments do not share the same laryngeal feature, which affects the realization of the $\mathrm{T}$ tone in the $\mathrm{AP}$ underlying tonal pattern (THLHa).

1. 사실은 문희가 재우에게 연을 만들어준 동료를 (간호했는데)

2. 사실은 민희가 정애에게 도시락을 싸준 숙모를 (동정했지만)

3. 사실은 영아가 찬호에게 신분증을 돌려준 경찰을 (의심하더니)

4. 있잖아 유라가 진우에게 편지를 보낸 이웃을 (찾아내더니)

5. 근데 말야 민우가 정수에게 물건을 주문해준 점원을 (나무랐지만)

6. 근데말야 인우가 재희에게 정수기를 판 고모를 (구박하더니)

7. 있잖아 영미가 정희에게 노래를 불러준 부인을 (따라갔더니)

8. 있잖아 미나가 진희에게 사진을 보여준 소녀를 (괴롭혔는데)

9. 있잖아 유미가 진아에게 가방을 사준 소년을 (찾아갔는데)

10. 사실은 영희가 주희에게 밥을 해 준 식모를 (위로하더니)

11. 있잖아 영애가 정아에게 지갑을 찾아준 직원을 (쫓아갔지만)

12. 근데말야 영우가 정우에게 돈을 꿔준 친척을 (외면했는데) 
13. 사실은 미라가 병희에게 직장을 알선해 준 선배를 (배신했지만)

14. 사실은 미래가 종수에게 선물을 준 조카를 (혼냈는데)

15. 근데말야 나미가 정미에게 도박을 가르친 애인을 (무시하더니)

16. 근데말야 미애가 재호에게 문제를 설명해준 청년을 (해고했는데)

17. 있잖아 은아가 진수에게 책을 빌려준 교수를 (배웅했지만)

18. 근데말야 미미가 영태에게 연락처를 남긴 검사를 (피해다녔지만) 